\title{
Paper
}

\section{Outlining a control system for regional conference websites: The Econometric Society conferences case}

\author{
Soumitra K. Mallick \\ is an Assistant Professor (Reader) at the Indian Institute of Social Welfare \& Business Management, Kolkata, in the areas of \\ Finance \& Economics. He obtained his B.Comm (Hons.) from Calcutta University, CA, from the Institute of Chartered Accountants \\ of India, New Delhi, and his Ph.D. in Economics from New York University. \\ Keywords: econometric society congress websites, coordination, web-based \\ dissemination, journal publications, locational rent, addition of frames
}

Abstract This paper outlines a hierarchical model for managing conference websites taking the websites of the various congresses of Econometric Society as the concrete case, and discusses some steps in implementation. The issue of timely "clusters" of the various regional meetings is integrated with the website and the journal publications by comparing website information and venue information and drawing implications of the economic theory of rent.

Journal of Digital Asset Management (2007) 3, 325-328. doi:10.1057/palgrave.dam.3650109

\section{INTRODUCTION}

The Econometric Society is an organization involved in the initiation and dissemination of economic research information. The organization is divided into regional branches spread over six geographical regions viz. North America, Latin America, Europe, South and South East Asia, Far East and Australasia. Each of these regional groupings holds conferences with various periodicities - twice a year for North America, twice a year for Europe, once every two years for Latin America and Australasia and once every four years for the others. The World Congress is held once every five years. Each of these regional conferences has research papers, which easily run into 50s organized by areas of specialization (Microeconomics,

Soumitra K. Mallick Indian Institute of Social Welfare \& Business Management, Management House, College Square West, Kolkata 700 073, India. E-mail: smallick@iiswbm. edu
Macroeconomics, etc) and by form (Presidential address, invited lectures, roundtables, paper sessions).

The build-up to each regional conference involves pre setting up a venue and a call for papers in response to which research work is submitted within a specified deadline for peer review and dissemination. For each such congress, the deadline is usually three months from the date of announcement and the time taken for refereeing and final selection is another three months, so that the final output in the form of the conference paper takes at least about six months to be organized and turned into a listing on the website for public viewing. This process of production and dissemination of research information thus takes at least six months, during which time not all effort is converted into final WebPages. The production process is also characterized by the fact that the final conferences are held at various regional venues with standard infrastructure requirements for holding such conferences, which involve several research personnel as well as support staff to organize the events and achieve the purpose of review and limited dissemination.

Over five-year periods, the six regional conferences are held and finally the world congress is held. Along with this, the 
Econometrica is published six times a year, which means over a five-year period there are 30 issues. A cursory look at any one issue highlights the fact that out of the 15 odd papers that make it to the issues, some have credits given to some of the congresses, some to the regional ones, while some to the world congress occasionally. This creates a disorder in the minds of any observer who tries to tie up the various forums of the Econometric Society into an organized whole. The problem is particularly identified in the presence of the web-based dissemination. Not only is there a "real problem" of coordinating the various forums there is a "virtual problem" of coordination. This note is meant to highlight only the "virtual problem." The real problem should take into account the "virtual problem," and hence is left outside the purview of this short note ("real problems" refer to the problems associated with dissemination through paper sessions and addresses at the congress venue while a "virtual problem" refers to the problems associated with dissemination through website postings at the congress website).

The next section discusses the possible elements of the production function of research information by the congresses taken in parts and then as a whole. The subsequent section discusses the coordination problems involved, and the final section presents the conclusion.

\section{PRODUCTION FUNCTION FOR WEB-BASED CONFERENCE PAPERS}

In discussing production functions for web-based conference papers, I first discuss the regional conferences and then the world congress. "The" world congress refers to a particular congress within any particular five-year period clustered with the preceding regional congresses.)

\section{Case I: Regional congress websites}

The inputs involved in the regional congress websites can be itemized as follows:

(a) electronic equipment involved, (b) energy involved, (c) office space involved, (d) labor to set up the web pages and (e) labor to maintain and operate the web pages. The output involves the papers hosted on the site during and after the conference. The first point to be noted here is that all these items are incremental over and above the "real costs" involved in the setting up of conferences as has already been stated.

The next point is that the pricing of the inputs in the first three cases, which is usually done on a "time sharing" basis with the venue(s), can be classified as the capital cost. This cost can both be estimated on the basis of direct money cost or on some notional shadow basis depending on the agreement of the "Congress Committee" with the venue(s). For example if the conference is held at the department of Economics, Tel Aviv University, then the rents paid for using the computer laboratory, the mainframe and building of Tel Aviv University can be included here, while the rent paid to the host portal should be included.

Ricardo's principles require that whenever rent of some kind is involved the location has to be a key factor. This is a particularly important point in assessing the differential rents associated with real locations as opposed to virtual locations. For example in the above example rents paid for using computer laboratories at Tel Aviv University would be different if the conference were to be held at University of Cairo, simply because land prices are different. Besides, the state of computing technology available in Israel may be very different from the state of computing technology available in Egypt (although they both meet the minimum requirements for holding the conferences at Tel Aviv University and University of Cairo, respectively) simply because of differential diffusion of technology across two countries within the same region. Thus, a vital input of the production function would involve various types of capital rents, which would require planning and coordination in order to be measured properly.

In assessing the labor inputs of web-based conference sites, the vital point is that again economies of scale can be attained by hosting the websites from different locations depending on the skill types of computing and scientific support staff available. In such a situation, direct wages involved or apportioned wages on the basis of time-sharing will form the inputs. Coordination problems arise with the time of arrival of refereed papers and their hosting as also the number of revisions they undergo. 
If there is a system of scrutiny at large based on web-hosted papers, continuous monitoring of such objections along with the responses involved will require a continuous "semi online" web monitoring and editing so that the true purposes of virtual dissemination are factored into the production function. A coordinated regional conference website production function will thus be an ex post construct taking into account the rental costs associated with regional congresses set off against the returns to scale effect of globalized web-based dissemination.

\section{Case II: World congress website}

In preparing this note, it has been assumed as has already been mentioned that every world congress is clustered with the previous regional congresses over a five-year period following some objectives, for example, tracing a particular set of problems. (As far as I know, there is nothing explicitly mentioned in the world congress websites, which makes this a realistic assumption.)

The set of inputs involved in preparing world congress websites along with the research papers are similar to the regional congress websites although they are typically larger. The outputs are also similar, except that the world congress should coordinate the relevant regional conferences. This output on the world congress website depends of course on the hierarchical model followed for the regional and world congresses. If the common link providing for clustering is flow of ideas then in a horizontally integrated cluster the world congress website should list papers on certain topics that are not discussed in the regional conferences while in a vertically organized setting the comments received at the regional conferences should mature into setting up the topics and papers in the world congress website. (On hierarchical organization of information, see for eg Radner and Van Zandt's ${ }^{1}$ paper on hierarchies, Picchione and Rubinstein's ${ }^{2}$ paper on the organization of information in repeated bargaining games and Binmore's ${ }^{3}$ paper on repeated automata.)

Thus, the objective of the world congress website in its relation with respect to the regional congress websites within the same cluster of five years should define the production function of the world congress website.

\section{ELECTRONIC INTEGRATION - THE WORLD CONGRESS WEBSITE}

Depending on the nature of the relation between the world congress website and the regional congress websites, various types of coordination problems arise. This is the main problem identified here.

In a horizontal type of organization, the comments received from the various meeting websites can be used to set up the topics or papers for the world congress websites. In a vertical type of organization, the comments and communications from the regional conferences should be coordinated to lead to the world congress website and the measure of the inputoutputs of the world congress should be so done such that the cluster is integrated.

This will ensure efficient utilization of the capital rent involved in the web-based dissemination by Econometric Society Congresses. It may be conjectured that since research information can give rise to increasing returns to scale if the returns are measured appropriately, the entire aggregation procedure already discussed may very well involve increasing returns complicating the last stage of dissemination, that is, through the journal Econometrica.

\section{CONTROL SYSTEM OUTLINE}

The Journal Econometrica is published six times a year. Assuming each issue publishes 12 papers over a year, the number of papers printed is 72 . Over five years, this comes to 360 . Assuming each regional conference covers 20 topics with three papers each and the presidential address and the invited lectures, the total comes to about 65 . That makes the total number of papers over five years with 30 regional conferences 1,950. Adding another around 50 papers of the world congress, the total comes to about 2,000 (the number of meetings has been obtained from www.econometricsociety.org/pastmeetings. asp $^{4}$ by counting the number between 2001 and 2005 both years inclusive, and includes all the meetings leading up to the world congress in 2005). There is obviously a gap of about 1,640 right away. This may not be much if papers presented at other conferences are not accepted for Econometrica. This, however, is not possible considering the importance of intersocietal 
relationship and cross-specialization, which means that a paper may be presented in some other conference but may also be relevant for Econometrica. Thus, networking with other associations can result in excess supply of papers for Econometrica although these have been peer reviewed and accepted for Econometric Society conferences.

A. Rubinstein has pointed out that one of the main problems that may be faced by this program is that it may be hard to implement because authors may not always be willing to submit their papers for journal publication, at least not right away. But this only complicates the problem outlined here by making it dynamic. It would be difficult to envisage authors who would not want to publish their papers at a journal of the rank of Econometrica, once they get themselves accepted at an Econometric Society conference. I think this is an open problem.

There is nothing contained in conference websites that promises a conduit between conference websites and the journal (which is also available online now). There is no natural integrating process that can passively add up frames from conference websites and add them up to give rise to the journal websites over a coordinated period of time. The problem is that there may not be a readily available policy that provides for the transformation "actively" either.

As a result, the electronic integration of dissemination of research by the Econometric Society through all the possible websites under its direct command is divergent. This may create problems if, for example, the society were to estimate the value of the information hosted over a five-year period. Besides, if paperwork reduction is to follow (as required by, say, the Paperwork Reduction Act in the United States, which applies to Government paperwork only but is suggestive of a general economy wide policy) for scientific papers, what is at present a compartmentalized virtual problem, involving the web-based dissemination alone will become a real problem too because that will be the only form of outlet.

Hence, a systematic hierarchical production function for the various conference websites and the journal of the Econometric Society is necessary. This note has suggested that this be organized into five-yearly time clusters over which the various production functions will have a basis for specification and coordination. The possible inputs in such production functions have been discussed. The relation between real and virtual sections in the production and dissemination of research information has been pointed out. The problem associated with rent and the scale effects of globalized web dissemination, which reduces the impact of regional rents for the Econometric Society, is highlighted.

\section{Acknowledgments}

The author thanks A. Rubinstein and the Econometric Society for initiating this research and V. Zwass, Arunava Sen and two earlier referees for helpful discussions and comments. The usual disclaimer applies.

\section{References}

1 Radner, R. and Van Zandt, T. (2001) 'Real time decentralized information processing and returns to scale', Economic Theory, Vol. 17, pp. 545-575.

2 Picchione, M. and Rubinstein, A. (1993) 'Finite automata play a repeated extensive game', Journal of Economic Theory, Vol. 61, pp. 160-168.

3 Binmore, K. (1992) 'Evolutionary stability in repeated games played by finite automata', Journal of Economic Theory, Vol. 57, pp. 278-305.

4 www.econometricsociety.org/pastmeetings.asp. 